\title{
The dependence of sorbed copper and nickel cyanide speciation on ion exchange resin type
}

\author{
Versiane A. Leão ${ }^{\mathrm{a}, 1}$, Grant C. Lukey ${ }^{\mathrm{a}}$, Jannie S.J. van Deventer ${ }^{\mathrm{a}, *}$, \\ Virginia S.T. Ciminelli ${ }^{b}$ \\ ${ }^{a}$ Department of Chemical Engineering, The University of Melbourne, Parkville, Victoria 3010, Australia \\ ${ }^{\mathrm{b}}$ Department of Metallurgical and Materials Engineering, Universidade Federal de Minas Gerais. Rua Espírito Santo, 35. Belo Horizonte, \\ $M G, 30160.030$, Brazil
}

Received 17 October 2000; accepted 20 February 2001

\begin{abstract}
The present study investigates the influence of functional group structure and resin matrix on the speciation of copper and nickel cyanides sorbed onto two commercially available ion exchange resins. Batch experiments were performed using synthetic copper and nickel solutions containing 50 and $200 \mathrm{mg} / \mathrm{L}$ free cyanide, respectively. Despite the presence of $\mathrm{Cu}(\mathrm{CN})_{3}^{2-}$ and $\mathrm{Cu}(\mathrm{CN})_{4}^{3-}$ in solution, it has been found using Raman spectroscopy that the Imac HP555s resin, which has a polystyrene-divinylbenzene matrix, loads predominantly the $\mathrm{Cu}(\mathrm{CN})_{3}^{2-}$ complex. In contrast, the polyacrylic resin, Amberlite IRA958, sorbed significant amounts of both $\mathrm{Cu}(\mathrm{CN})_{3}^{2-}$ and $\mathrm{Cu}(\mathrm{CN})_{4}^{3-}$. It has been found that the speciation of nickel cyanide sorbed onto each resin was the same. A recently developed mathematical model based on statistical thermodynamic principles has been used as a tool to understand further the equilibrium sorption of copper and nickel cyanide complexes onto each resin studied. A higher sorption energy for nickel compared to copper has been observed for the sorption onto Imac HP555s. In contrast, the sorption energy for copper was found to be higher than for nickel for the polyacrylic resin, Amberlite IRA958. The values of the model parameters obtained were correlated with the chemical features of each complex in solution as well as sorbed onto the resins. (c) 2001 Elsevier Science B.V. All rights reserved.
\end{abstract}

Keywords: Copper cyanide complexes; Speciation; Raman spectroscopy; Ion exchange

\section{Introduction}

The processing of gold-copper ores is at present a major focus of attention in the minerals industry.

\footnotetext{
* Corresponding author. Tel.: +61-3-8344-6620; fax: +61-38344-4153.

E-mail address: jannie@unimelb.edu.au (J.S.J. van Deventer).

${ }^{1}$ Permanent address: Department of Metallurgical and Materials Engineering, Escola de Minas, Universidade Federal de Ouro Preto, Minas Gerais, Brazil.
}

The widespread presence of ores with low gold content as well as high levels of base metals is challenging the research community to identify and develop new methods and/or technologies for the cost-effective processing of these types of ores. The processing of gold-copper ores is currently under investigation and some alternatives are being presented. Since the majority of copper minerals are soluble in cyanide solutions, chrysocolla and chalcopyrite being the main exceptions [1], the main challenge is to decrease the cyanide consumption 
during leaching. Some alternatives have been proposed such as the use of selective flotation, leaching with ammonia-cyanide solutions and also cyanide recycling.

In the case of cyanide recycling, the proposed methods usually involve the acidification of cyanide solutions. In the AVR process, the cyanide solution is acidified (Acidification), then contacted with air in a counter-current tower to volatilise the soluble cyanide (Volatilisation). Finally, the $\mathrm{HCN}$-air mixture is neutralised (Reneutralisation) in a caustic solution $\left(\mathrm{NaOH}\right.$ or $\left.\mathrm{Ca}(\mathrm{OH})_{2}\right)$. Riveros et al. [2] showed the feasibility of applying the AVR process to solutions containing high amounts of copper cyanides. The standard AVR practice requires the use of clarified solutions or barren bleeds. The application of the AVR process to pulps must be done at higher $\mathrm{pH}$ (usually 5.5 to $7.5 \mathrm{pH}$ range). However, copper cyano-complexes start to decompose at a $\mathrm{pH}$ lower than 3 and so the acidification in the abovementioned $\mathrm{pH}$ range does not allow the copper-bound cyanide to be released $[3,4]$.

Recently developed resin technology can be used for the recycling of cyanide from pulps as well as from clarified solutions. In this process, ion exchange resins are used to sorb and concentrate the cyano-complexes that have been leached from the ore. The resins are then screened from the pulp and eluted. Current examples of this technology are the Augment and the Vitrokele processes [5,6].

Leão and Ciminelli [7] have studied previously the sorption of metal cyano-complexes onto strong base resins from solutions containing high concentrations of copper and minor amounts of iron and nickel. The objective of the work was to identify a suitable resin for cyanide recycling in the processing of gold-copper ores. It was observed by Leão and Ciminelli [7] that resins having a polyacrylic matrix possess a greater affinity for copper cyanide compared to nickel cyanide, while for polystyrene-based resins the converse is observed. It was proposed that this selectivity was due to the physico-chemical features of each resin (matrix and exchange groups) and also the solution, however, no direct measurement of metal speciation was undertaken. In the present work, Raman spectroscopy is used to determine the speciation of copper and nickel cyano-complexes in solution and also sorbed onto each ion exchange resin. It is important to identify the metal cyanide speciation because this information is used to estimate parameter values in the mathematical model that has been developed to describe the equilibrium sorption behaviour of each system studied.

As the sorption step is dependent on the physicochemical features of both the solution and the resin it is necessary to assess the loading for different concentrations of the metals in solution. This is particularly important in the case of the gold-copper ores located on a transition zone between the sulphides at the bottom of the mine and the upper part where the oxide ore is found. This transition zone usually presents a rather irregular copper content [8]. In this regard, the modelling of these conditions allows the prediction of sorption equilibria when the concentrations of these metals in solution change significantly.

Many mathematical models have been proposed for the equilibrium sorption of ions onto soils, activated charcoal and also ion exchange resins. These models are effective in predicting the loading of the sorbent in relatively simple systems (no complex species in solution, homogeneous solid phase and low ionic strength). However, they usually fail in predicting sorption equilibria in more complex systems such as those found in hydrometallurgical operations-high ionic strength, different complexes in solution.

In the present work the mathematical model originally formulated by De Kock [9] has been used as a tool to understand further the equilibrium sorption of copper and nickel cyanide onto two commercially available ion exchange resins. This model has recently been used to describe the equilibrium sorption of gold and copper cyanide onto a variety of ion exchange resins in non-saline and highly saline solutions $[10,11]$. It is based on the principles of statistical thermodynamics as well as the Metropolis Monte Carlo (MMC) numerical method. An important aspect of this modelling approach is that it does not use any solely empirical parameters. It is therefore possible to include fundamental information of the system in order to facilitate easier estimation of parameters. It is important to note that the emphasis of the current work is to compare the equilibrium sorption of copper and nickel cyanide onto ion exchange resins for the purpose of recycling the bound cyanide. The two resins investigated have a different 
functional group structure and also resin matrix. Therefore, the present work investigates the sorption of copper and nickel cyano-complexes on resins with different affinities for the metals. The effect of speciation of each metal cyanide complex in solution as well as sorbed onto the resin is discussed. The present study combines the results obtained from Raman spectroscopy and also the mathematical model to develop for the first time a complete understanding of the equilibrium sorption of copper and nickel cyanide onto different ion exchange resins.

\section{Experimental procedures}

\subsection{Ion exchange resins}

Two commercially available ion exchange resins were selected for the sorption experiments. Both resins are macroporous and contain strong base quaternary ammonium functional groups. Imac HP555s is a polystyrene-based resin containing the triethylammonium as the exchange group. Amberlite IRA958 is a polyacrylic resin that contains the trimethylammonium functionality. Both resins were obtained from Rohm and Haas, France. Prior to each experiment, the resin was allowed to swell in distilled water.

\subsection{Preparation and Raman analysis of metal cyanide solutions and resins}

Copper and nickel cyanide solutions $(0.01 \mathrm{M})$ for Raman analysis were prepared by dissolving either $\mathrm{CuCN}$ (99\%, Aldrich) in a potassium cyanide (98\%, Aldrich) solution $(\mathrm{CN} / \mathrm{Cu}=3.5)$ or potassium tetracyanonickelate(II) hydrate $\left(\mathrm{K}_{4} \mathrm{Ni}(\mathrm{CN})_{4} \times \mathrm{H}_{2} \mathrm{O}\right.$, F.W. 240.99, Aldrich) in distilled water. An additional quantity of potassium cyanide (98\%, Aldrich) was added to each solution in order to increase the concentration of free cyanide to approximately 250 or $1000 \mathrm{mg} / \mathrm{L}$. This was necessary to ensure that these solutions had the same $\mathrm{CN} / \mathrm{Cu}$ and $\mathrm{CN} / \mathrm{Ni}$ molar ratios as the solutions used during the sorption experiments. It is important to note that a high concentration $(0.01 \mathrm{M})$ of each metal in solution was necessary in order to obtain well-defined Raman spectra. No attempt was made to alter the $\mathrm{pH}$ of either the copper or nickel cyanide solution.
Amberlite IRA958 (1 mL) and Imac HP555s (1 $\mathrm{mL}$ ) were loaded by contacting each resin with a solution containing $0.002 \mathrm{M}$ copper and nickel cyanide. The amount of resin used was chosen in order to obtain significant sorption of each metal on both resins. Potassium cyanide (98\%, Aldrich) was added to these solutions in order to increase the concentration of free cyanide to approximately 50 or $200 \mathrm{mg} / \mathrm{L}$. Consequently, the $\mathrm{CN} / \mathrm{Cu}$ and $\mathrm{CN} / \mathrm{Ni}$ molar ratio in these solutions was the same as the solutions described previously.

A Renishaw Raman Microscope (Ramascope 2000) was used to obtain the Raman spectra. A linearly polarised $\mathrm{HeNe}$ laser (Spectra Physics model \#127, $\lambda=632.8 \mathrm{~nm}, 60 \mathrm{~mW}$ output) was used as the excitation source. The Raman spectra of all solutions were obtained by placing the cyanide solutions directly under the objective of the microscope. Optimum Raman spectra of each fluid were obtained by using a $5 \times$ objective to focus the laser source approximately $10-20 \mu \mathrm{m}$ below the surface of the solution. Directly focussing the laser source onto the surface of the fluid was not possible as the height of the fluid decreased with time due to evaporation of the solution. The spectra of the resins were obtained by placing one resin bead directly under the objective of the microscope. In order to minimise the effects of the conversion of free cyanide to cyanate on the spectra, large numbers of short scans were accumulated to yield the 10 -min integration time. The spectra presented are the raw data with no post-accumulation processing.

\subsection{Determination of cyanide in solution}

The concentration of cyanide in solution was determined by using the silver nitrate titrimetric method [12]. This method is based on the formation of $\left[\mathrm{Ag}(\mathrm{CN})_{2}\right]^{-}$as silver nitrate is added to a cyanide solution. The end point of the titration is reached when a silver sensitive indicator detects an excess of silver. Unless otherwise stated, rhodinine (Rowe Scientific, AR Grade) was used as an indicator. The end point was taken to be the final colour change from canary yellow to salmon hue. The presence of labile copper cyanide interferes with the end point by the loss of cyanide associated with the copper complex. 
As a result, an increase in the value of 'free' cyanide is obtained. This effect was minimised by the dilution of samples [12]. In the present work the loss of cyanide during each sorption experiment was defined as the change in the concentration of free cyanide, determined at the beginning and at the end of each experiment. The loss of cyanide for solutions containing an initial cyanide concentration of $200 \mathrm{mg} / \mathrm{L}$ was between 15 and $60 \mathrm{mg} / \mathrm{L}$. For solutions having an initial cyanide concentration of $50 \mathrm{mg} / \mathrm{L}$, the loss of cyanide was between 10 and $40 \mathrm{mg} / \mathrm{L}$. This indicates that the loss of cyanide is linked to the initial copper concentration in the solution.

\subsection{Equilibrium sorption of metal cyanides onto ion exchange resins}

Synthetic solutions of copper(I) cyanide were prepared by mixing $\mathrm{CuCN}$ (99\%, Aldrich) and potassium cyanide $(98 \%$, Aldrich) at a $\mathrm{CN} / \mathrm{Cu}$ molar ratio of 3.5. Nickel cyanide solutions were prepared by dissolving potassium tetracyanonickelate(II) hydrate $\left(\mathrm{K}_{4} \mathrm{Ni}(\mathrm{CN})_{4} \times \mathrm{H}_{2} \mathrm{O}\right.$, F.W. 240.99, Aldrich $)$ in distilled water. These solutions were placed in PVC bottles and kept refrigerated at $4^{\circ} \mathrm{C}$ until used.

To assess the loading of copper and nickel cyano-complexes on both resins the concentration of each metal in aqueous solution was varied in a way that allowed the molar fraction of metals on the resin to vary between 0 and 1 . Sorption tests were performed in baffled $1 \mathrm{~L}$ PVC containers that were attached to a simultaneous overhead stirrer bench that had the capacity to stir 28 containers. Each container was stirred at $200 \mathrm{~min}^{-1}$ for $24 \mathrm{~h}$. This time was sufficient for the attainment of a pseudoequilibrium. Each container was immersed in a water bath and the temperature kept constant at $30^{\circ} \mathrm{C}$. Before agitation, copper and nickel solutions of differing metal concentrations were prepared by mixing specific amounts of the reserved copper and nickel solutions. Using potassium cyanide solution (KCN $98 \%$, Aldrich), the concentration of free cyanide in each container was adjusted to either 50 or 200 $\mathrm{mg} / \mathrm{L}$ approximately. These systems are referred to hereafter as 50 and $200 \mathrm{mg} / \mathrm{L}$ cyanide solutions. One milliliter of resin was used throughout the experiments.

A sample of the solution in each container was taken at the beginning and at the end of each experi- ment. The metal content in the aqueous phase was determined by Inductively Coupled Plasma Optical Emission Spectroscopy (ICP-OES). This enabled the metal content on the resin to be determined by mass balance. The $\mathrm{pH}$ of each solution varied between 10.7 and 10.2 for the experiments using $200 \mathrm{mg} / \mathrm{L}$ free cyanide and 10.4-9.7 for the experiments using $50 \mathrm{mg} / \mathrm{L}$ free cyanide. No attempt was made to maintain the $\mathrm{pH}$ or the free cyanide concentration in each container during the sorption run.

\section{Description of the mathematical model}

A complete derivation of the mathematical model used in this study has been presented by De Kock [9]. The model has been reformulated and applied recently to the equilibrium sorption of gold and copper on a series of polystyrene-based ion exchange resins $[10,11]$. In the present work the model is used as a tool to gain further insight into the sorption behaviour of copper and nickel on two ion exchange resins which have different functionalities and matrices. The model is used to provide further support to the observations made using Raman spectroscopy.

The mathematical model used is based on the minimisation of the Gibbs free energy during sorption. Using the Boltzmann criterion $[10,11]$ it is possible to formulate a system of equations that describe sorption equilibria for systems that exhibit ideal properties. However, to successfully describe the equilibrium sorption in real systems, modifications are made to the model to incorporate the non-ideal sorption behaviour given below.

(i) Heterogeneous surfaces: Heterogeneous surfaces are modelled by dividing the surface of the sorbent into a series of equally sized homogeneous patches. The energy of each homogeneous patch is determined from a statistical distribution. In the present work, it has been found that the Normal cumulative distribution function adequately describes the heterogeneous surface of each resin studied.

(ii) Lateral interactions: The Coulombic interaction between sorbed species such as copper and nickel cyanide on the resin may be significant and therefore these possible interactions must be incorporated into the model. Intuitively, higher interaction energies would be expected for systems where the 
sorbed molecules are in close proximity. The interaction energies are considered constant for each system and if their values are positive, the species on the surface repel or destabilise each other due to Coulombic forces. This type of interaction corresponds to an increase in the total system energy.

(iii) Selective sorption: Selective sorption is associated with particular features of the sorption sites on the resin, for example steric effects or the nature of the matrix. To incorporate selective sorption into the model, each patch is divided into separate areas according to the number of species being modelled. The equilibrium loading of each species in each area can then be determined. This allows an estimate of the loading for each patch to be made using the relative size of each area to perform a weighted summation.

(iv) Irreversible sorption: The possibility of the irreversible sorption of species onto the sorbent is also incorporated into the mathematical model. The irreversibility parameter can have values greater than 0 and less than or equal to 1 . The value of unity for the irreversibility parameter corresponds to completely reversible sorption.

In the present study the fit of the model to the experimental data was determined as follows:

$\%$ Error $=\frac{100}{m} \times \sum_{1}^{m}\left|\frac{x_{i, \operatorname{Exp}}-x_{i, \operatorname{Pr}}}{x_{i, \operatorname{Pr}}}\right|$

where $x_{i, \operatorname{Exp}}=$ the experimental equivalent fraction of species $i . x_{i, \mathrm{Pr}}=$ the predicted equivalent fraction of species $i . m=$ the number of equilibrium data points.

\section{Results and discussion}

Table 1 presents the assignments of Raman peaks observed in solution for metal cyano-complexes. The $\mathrm{Cu}(\mathrm{CN})_{4}^{3-}$ species exhibits peaks at 2078 and 2094 $\mathrm{cm}^{-1}$ which are assigned to the weak asymmetric and the strong symmetric vibrational stretching of the complex respectively. The peak at $2078 \mathrm{~cm}^{-1}$ overlaps with the vibrational stretch of free cyanide, which occurs at a similar wavelength [13]. The peak at $2094 \mathrm{~cm}^{-1}$ also corresponds to the weak asymmetric vibrational stretching of $\mathrm{Cu}(\mathrm{CN})_{3}^{2-}$. Finally,
Table 1

Raman assignments for cyano-complexes in aqueous solution

\begin{tabular}{llll}
\hline $\begin{array}{l}\text { Metal } \\
\text { species }\end{array}$ & $\begin{array}{l}\nu, \text { polarised } \\
\left(\mathrm{cm}^{-1}\right)\end{array}$ & $\begin{array}{l}\nu, \text { depolarised } \\
\left(\mathrm{cm}^{-1}\right)\end{array}$ & Reference \\
\hline $\mathrm{Cu}(\mathrm{CN})_{2}^{-}$ & 2137 & & {$[13]$} \\
$\mathrm{Cu}(\mathrm{CN})_{3}^{2-}$ & 2108 & 2094 & {$[13]$} \\
$\mathrm{Cu}(\mathrm{CN})_{4}^{3-}$ & 2094 & 2078 & {$[13]$} \\
$\mathrm{Ni}(\mathrm{CN})_{4}^{2-}$ & 2146 & 2138 & {$[14]$} \\
$\mathrm{Ni}(\mathrm{CN})_{5}^{3-}$ & 2128 & 2114 & {$[14]$} \\
$\mathrm{CN}^{-}$ & 2077 & & {$[13]$} \\
\hline
\end{tabular}

the peak at $2108 \mathrm{~cm}^{-1}$ is assigned to the symmetric (strong) vibrational stretching of $\mathrm{Cu}(\mathrm{CN})_{3}^{2-}$ [13].

The Raman spectra obtained for copper cyanide solution containing 250 and $1000 \mathrm{mg} / \mathrm{L}$ free cyanide are shown in Fig. 1. It is important to note the change in the relative intensities of the peaks at 2108 $\mathrm{cm}^{-1}\left(\mathrm{Cu}(\mathrm{CN})_{3}^{2-}\right)$ and $2078 \mathrm{~cm}^{-1}\left(\mathrm{Cu}(\mathrm{CN})_{4}^{3-}\right)$ as the concentration of free cyanide in solution is increased from 250 to $1000 \mathrm{mg} / \mathrm{L}$. For the copper cyanide solution containing $250 \mathrm{mg} / \mathrm{L}$ free cyanide, the existence of peaks at 2108 and $2078 \mathrm{~cm}^{-1}$ indicates the presence of both $\mathrm{Cu}(\mathrm{CN})_{3}^{2-}$ and $\mathrm{Cu}(\mathrm{CN})_{4}^{3-}$ in solution. The greatest relative intensity is observed for the peak at $2094 \mathrm{~cm}^{-1}$. As discussed previously, this peak is attributed to the asymmetric vibrational stretch of $\mathrm{Cu}(\mathrm{CN})_{3}^{2-}$ and also the strong symmetric stretch of $\mathrm{Cu}(\mathrm{CN})_{4}^{3-}$. As shown by Fig. 1, the relative intensities of the above-mentioned peaks are changed as the free cyanide concentration is increased from 250 to $1000 \mathrm{mg} / \mathrm{L}$. For a free cyanide concentration of $1000 \mathrm{mg} / \mathrm{L}$, the peak at $2078 \mathrm{~cm}^{-1}$ (assigned to $\mathrm{Cu}(\mathrm{CN})_{4}^{3-}$ and $\mathrm{CN}^{-}$) has a greater relative intensity compared to the peak at $2108 \mathrm{~cm}^{-1}$ $\left(\mathrm{Cu}(\mathrm{CN})_{3}^{2-}\right)$. Furthermore, the peak at $2094 \mathrm{~cm}^{-1}$ (assigned to $\mathrm{Cu}(\mathrm{CN})_{3}^{2-}$ and $\mathrm{Cu}(\mathrm{CN})_{4}^{3-}$ ) has greater relative intensity than the peak at $2108 \mathrm{~cm}^{-1}$. These changes in peak height imply that the equilibrium [15] depicted in Eq. (2) is shifted to the right as the concentration of free cyanide is increased from 250 to $1000 \mathrm{mg} / \mathrm{L}$.

$$
\mathrm{Cu}(\mathrm{CN})_{3}^{2-}+\mathrm{CN}^{-} \leftrightharpoons \mathrm{Cu}(\mathrm{CN})_{4}^{3-} \quad \log K=1.5
$$

The Raman spectra obtained for the $\mathrm{Ni}-\mathrm{CN}-\mathrm{H}_{2} \mathrm{O}$ system are presented in Fig. 2. Although the formation of $\mathrm{Ni}(\mathrm{CN})_{5}^{3-}$ in solutions containing excess cyanide has been suggested previously [15], the peaks 


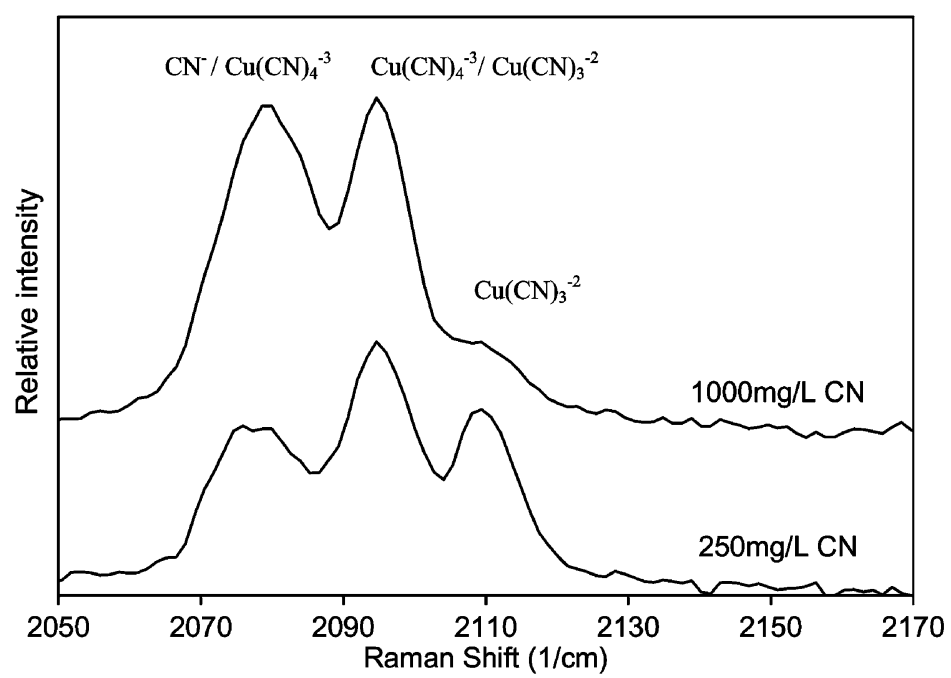

Fig. 1. Raman spectra of aqueous cuprous cyanide as a function of the free cyanide concentration.

at 2146 and $2138 \mathrm{~cm}^{-1}$ in Fig. 2 are assigned to the $\mathrm{Ni}(\mathrm{CN})_{4}^{2-}$ complex only. According to Terzis et al. [14] the pentacyanonickelate(II) complex is observed only in concentrated cyanide solutions $(7.8 \mathrm{M})$. However, even in the extreme conditions used by Terzis et al. [14] the total conversion of $\mathrm{Ni}(\mathrm{CN})_{4}^{2-}$ to $\mathrm{Ni}(\mathrm{CN})_{5}^{3-}$ was not observed. Consequently, the absence of peaks attributed to $\mathrm{Ni}(\mathrm{CN})_{5}^{3-}$ was expected in the current work because of the experimental conditions used $(250 \mathrm{mg} / \mathrm{L}$ and $1000 \mathrm{mg} / \mathrm{L}$ free cyanide).

The Raman spectra obtained for the Imac HP555s resin loaded with copper and nickel cyano-complexes are presented in Fig. 3. The Imac HP555s resin contains triethylammonium functional groups attached to a polystyrene-divinylbenzene matrix. It has been established previously that this resin has a high affinity for cyano-complexes with low charge

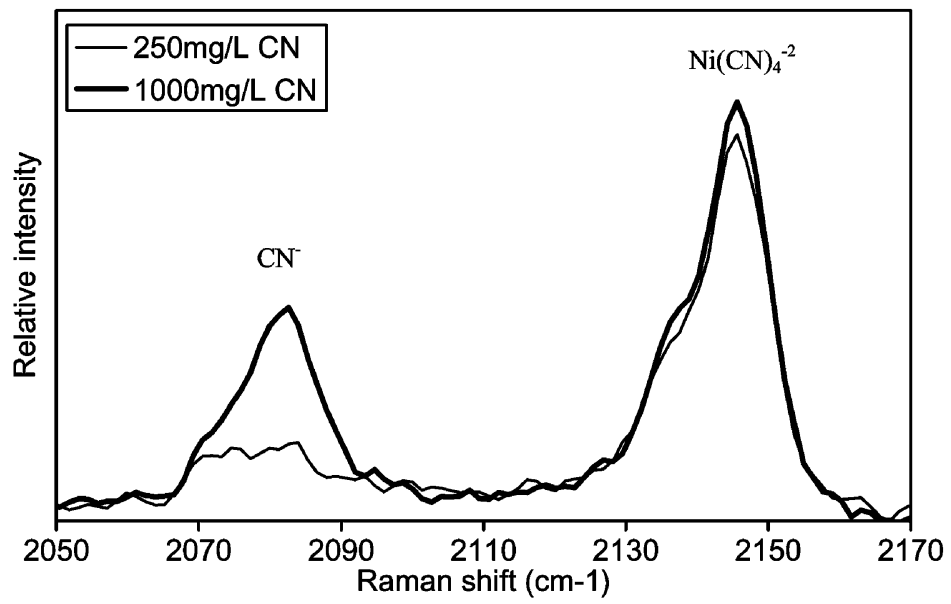

Fig. 2. Raman spectra of aqueous nickel cyanide containing 250 and $1000 \mathrm{mg} / \mathrm{L}$ free cyanide, respectively. Raman spectrum of cyanide solution (as KCN) showed peaks in the $2070-2090 \mathrm{~cm}^{-1}$ range. 


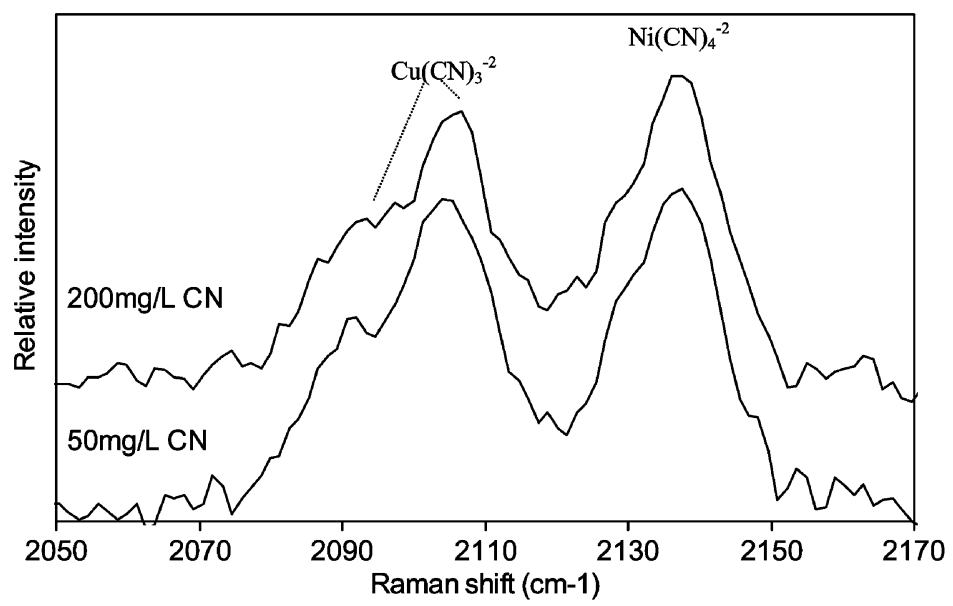

Fig. 3. Raman spectra for copper and nickel cyanides sorbed on the Imac HP555s resin. The peaks at 2094 and $2108 \mathrm{~cm}^{-1}$ are related to copper and the peak at $2137 \mathrm{~cm}^{-1}$ corresponds to the sorbed nickel cyano-complex. Resin loadings: $12.3 \mathrm{mgCu} / \mathrm{mL}$ resin and 16.3 $\mathrm{mgNi} / \mathrm{mL}$ resin for $50 \mathrm{mg} / \mathrm{L} \mathrm{CN}^{-}$solution; $11.4 \mathrm{mgCu} / \mathrm{mL}$ resin and $15.3 \mathrm{mgNi} / \mathrm{mL}$ resin for $200 \mathrm{mg}^{-\mathrm{L} \mathrm{CN}^{-}}$solution.

such as $\mathrm{Au}(\mathrm{CN})_{2}^{-}$[16], $\mathrm{Zn}(\mathrm{CN})_{4}^{2-}$ and $\mathrm{Ni}(\mathrm{CN})_{4}^{2-}$ compared to the cyano-complexes of copper and iron $[7,17,18]$. This sorption phenomenon was attributed to the steric hindrance of the triethylammonium functional group $[7,18]$.

A previous investigation by Leão et al. $[7,17]$ used both batch and column experiments to study the sorption behaviour of Imac HP555s. It was observed by Leão et al. [7,17] that for a solution containing a high concentration of copper and minor amounts of nickel and iron cyano-complexes, the Imac HP555s resin exhibited a high affinity for the nickel cyanocomplex while iron was rejected by the resin. Copper presented an intermediate behaviour. In particular for the batch experiments, which involved contacting $1 \mathrm{~g}$ of resin with $100 \mathrm{~mL}$ of a solution containing 500 $\mathrm{mg} / \mathrm{L} \mathrm{Cu}, 50 \mathrm{mg} / \mathrm{L} \mathrm{Ni}$ and $15 \mathrm{mg} / \mathrm{L} \mathrm{Fe}$, Leão and Ciminelli [7] observed the loading of nickel and iron to be $99 \%$ and $6 \%$, respectively. Copper exhibited an intermediate level of sorption with $63 \%$ being extracted from the solution. The behaviour of copper during sorption was credited to the formation of both $\mathrm{Cu}(\mathrm{CN})_{3}^{2-}$ and $\mathrm{Cu}(\mathrm{CN})_{4}^{3-}$ in solution. Consequently, for the experimental conditions used in the study by Leão and Ciminelli [7] copper was not completely rejected nor did the complex have a strong affinity for the resin. In the present work, Raman spectroscopy is used to investigate further the effect of metal cyanide speciation on the selectivity of ion exchange resins.

The Raman spectra presented in Fig. 3 clearly elucidate the speciation of copper and nickel cyanocomplexes sorbed on the Imac HP555s resin. As shown previously in Fig. 1, a copper cyanide solution containing a concentration of either 250 or 1000 $\mathrm{mg} / \mathrm{L}$ cyanide (this corresponds to the same $\mathrm{CN} / \mathrm{Cu}$ molar ratio used during the sorption of the metals on the resin) exhibits Raman peaks that are characteristic of both $\mathrm{Cu}(\mathrm{CN})_{3}^{2-}$ and $\mathrm{Cu}(\mathrm{CN})_{4}^{3-}$ complexes. Furthermore, the distribution of the copper cyanide complexes in solution was dependent upon the concentration of free cyanide. Fig. 2 also shows that nickel forms only the $\mathrm{Ni}(\mathrm{CN})_{4}^{2-}$ complex in solutions containing a concentration of 250 or 1000 $\mathrm{mg} / \mathrm{L}$ free cyanide, respectively.

Comparing Fig. 3 with Fig. 1 it can be seen that the weak asymmetric vibrational stretch at 2078 $\mathrm{cm}^{-1}$, assigned previously to the $\mathrm{Cu}(\mathrm{CN})_{4}^{3-}$, complex is not observed in the Raman spectra of the loaded resin. This result suggests that the Imac HP555s resin has a strong affinity for the $\mathrm{Cu}(\mathrm{CN})_{3}^{2-}$ complex. The peaks at 2108 and $2094 \mathrm{~cm}^{-1}$ in Fig. 3 are assigned to the strong and weak stretching modes of vibration of the $\mathrm{Cu}(\mathrm{CN})_{3}^{2-}$ complex, respectively. As the polarised peak of $\mathrm{Cu}(\mathrm{CN})_{4}^{3-}$ occurs at the same Raman shift of the depolarised 
(weak) peak of $\mathrm{Cu}(\mathrm{CN})_{3}^{2-}$, the peak at $2094 \mathrm{~cm}^{-1}$ alone cannot be used to identify the tetracyanocuprite complex. Fig. 3 shows clearly that the Imac HP555s resin has a strong affinity for the $\mathrm{Cu}(\mathrm{CN})_{3}^{2-}$ complex, despite a distribution of both $\mathrm{Cu}(\mathrm{CN})_{3}^{2-}$ and $\mathrm{Cu}(\mathrm{CN})_{4}^{3-}$ in solution (Fig. 1). The polystyrene-divinylbenzene matrix of Imac HP555s leads to the resin having a predominantly hydrophobic character. This hydrophobic character, combined with the steric hindrance associated with the triethylammonium functional group explains the strong affinity of the resin for $\mathrm{Cu}(\mathrm{CN})_{3}^{2-}$.

Jones and Penneman [19] have observed this sorption phenomenon previously for the silver cyanide system. Using infrared spectroscopy, Jones and Penneman [19] observed the formation of three different silver cyanide complexes in solution as the concentration of free cyanide was increased, viz. $\operatorname{Ag}(\mathrm{CN})_{2}^{-}$, $\mathrm{Ag}(\mathrm{CN})_{3}^{2-}$ and $\operatorname{Ag}(\mathrm{CN})_{4}^{3-}$. However, regardless of the concentration of free cyanide in solution, it was observed using infrared that only $\mathrm{Ag}(\mathrm{CN})_{2}^{-}$loaded onto the Dowex A-1 resin. Other peaks were observed in the infrared spectrum, however, these were unable to be assigned to $\mathrm{Ag}(\mathrm{CN})_{3}^{-2}$ or $\mathrm{Ag}(\mathrm{CN})_{4}^{-3}$.

Although the peak associated with the formation of $\mathrm{Cu}(\mathrm{CN})_{2}^{-}$in solution is not observed in Fig. 1, it is possible that this complex may be sorbed onto Imac HP555s due to the high affinity that this resin has for cyano-complexes with low charge. From Table 1 it can be seen that the Raman peak for the $\mathrm{Cu}(\mathrm{CN})_{2}^{-}$complex is located at $2137 \mathrm{~cm}^{-1}$. This means that the possible sorption of $\mathrm{Cu}(\mathrm{CN})_{2}^{-}$on the Imac HP555s resin cannot be determined from Fig. 3 because the $\mathrm{Cu}(\mathrm{CN})_{2}^{-}$peak overlaps with the peak assigned to the vibrational stretch of $\mathrm{Ni}(\mathrm{CN})_{4}^{2-}$ (Table 1). In an attempt to determine whether the $\mathrm{Cu}(\mathrm{CN})_{2}^{-}$complex does load onto the Imac HP555s resin, a separate sorption experiment was performed which loaded only copper cyanide species onto the resin. Although the Raman spectrum is not shown, the characteristic peak for $\mathrm{Cu}(\mathrm{CN})_{2}^{-}$was not observed on the Imac HP555s resin loaded only with copper cyanide. Therefore, provided that nickel cyanide does not affect the speciation of copper sorbed onto the resin, it can be inferred that $\mathrm{Cu}(\mathrm{CN})_{2}^{-}$ does not load onto the Imac HP555s resin.

The Raman peaks assigned to nickel cyanide indicate that the loading of this metal on Imac HP555s occurs without change in its coordination. The only nickel species observed in solution and also on the resin is the $\mathrm{Ni}(\mathrm{CN})_{4}^{2-}$ complex. It is noteworthy that the slight shift in the position of the peak assigned to $\mathrm{Ni}(\mathrm{CN})_{4}^{2-}$ in Fig. 3 compared with Fig. 1 can be attributed to the interaction of the nickel complex with the resin. Jones and Penneman [19] observed that the loading of the aurocyanide species onto resins occurs without any change of the gold-cyanide speciation. In aqueous solutions, gold forms only the $\mathrm{Au}(\mathrm{CN})_{2}^{-}$complex regardless of the amount of cyanide present in the solution or in the resin. Furthermore, Vernon et al. [20] and Fawell et al. [21] observed no speciation changes during the loading of copper, nickel and gold cyano-complexes on the IRA400 resin. Riveros and Cooper [22] also observed no change in the speciation of iron during sorption. In summary, the above-mentioned work has shown that the nature of the sorbed species is dependent upon the chemical structure of the resin as well as the chemistry of the sorption solution.

As shown by Figs. 4 and 5, the equilibrium sorption of copper and nickel on the Imac HP555s resin is predicted satisfactorily using the mathematical model described. As indicated by Table 2, a unimodal Normal distribution was used to describe the heterogeneity of the resin surface experienced by copper and also nickel. A recent study by Lukey et al. [10] modelled the loading of copper and gold on a series of polystyrene-based resins using a bimodal Normal distribution for copper and unimodal Normal distribution for gold. It was reasoned by Lukey et al. [10] that a bimodal distribution for copper was required due to the significant sorption of both $\mathrm{Cu}(\mathrm{CN})_{3}^{2-}$ and $\mathrm{Cu}(\mathrm{CN})_{4}^{3-}$ on the resins studied. As stated previously, the Imac HP555s resin used in the current work is highly selective for complexes with a low charge. In particular, it was established using Raman spectroscopy that the resin sorbs predominantly the $\mathrm{Cu}(\mathrm{CN})_{3}^{2-}$ complex (Fig. 3) despite the fact that both $\mathrm{Cu}(\mathrm{CN})_{3}^{2-}$ and $\mathrm{Cu}(\mathrm{CN})_{4}^{3-}$ exist in solution for the experimental conditions used in this work (Fig. 1). It was noted that due to the overlapping Raman peaks of the weak asymmetric stretch of $\mathrm{Cu}(\mathrm{CN})_{3}^{2-}$ with the strong symmetric vibrational stretch of $\mathrm{Cu}(\mathrm{CN})_{4}^{3-}$ it was not possible to conclude beyond doubt that only the $\mathrm{Cu}(\mathrm{CN})_{3}^{2-}$ sorbed onto the resin. However, the fact that a unimodal Normal 


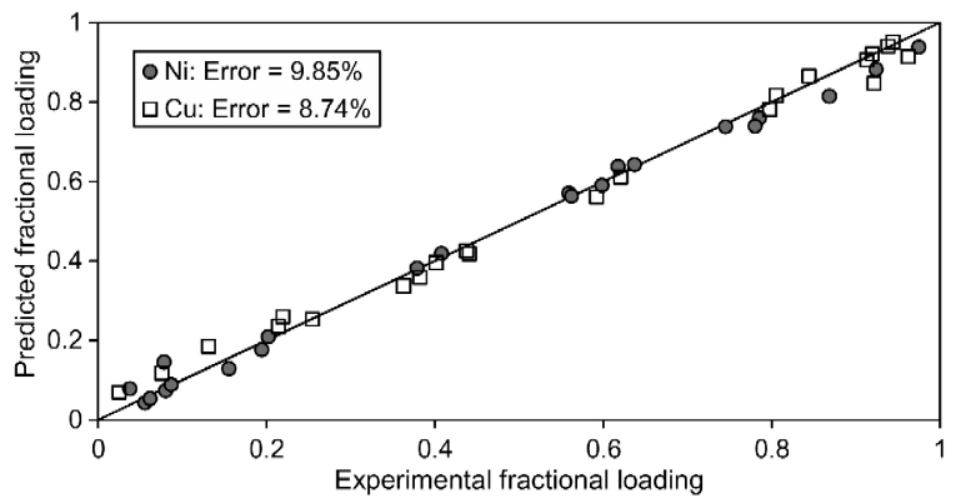

Fig. 4. A comparison between predicted and experimental copper and nickel loading on the Imac HP555s resin. Initial cyanide concentration: $50 \mathrm{mg} / \mathrm{L}$.

distribution more accurately describes the sorption of copper on Imac HP555s supports the contention that only the $\mathrm{Cu}(\mathrm{CN})_{3}^{2-}$ sorbs onto the resin.

As an approximation, the equivalent fraction of copper in solution was calculated using a charge of 2.5. This was necessary because it is not possible to determine the ratio of both copper cyanide species in solution. Although the nickel cyano-complex is square planar and the $\mathrm{Cu}(\mathrm{CN})_{3}^{2-}$ complex is trigonal planar, no improvement in the fit of the model was observed by limiting the surface area available for the sorption of copper or nickel (Table 2). This implies that although the copper and nickel complexes have different geometries, no selective sorption of either complex takes place on the Imac HP555s resin. This means that the same sorption sites are available for both complexes. In this regard the most important factor is the electrical charge of the complex. Due to the double charges of $\mathrm{Cu}(\mathrm{CN})_{3}^{2-}$ and $\mathrm{Ni}(\mathrm{CN})_{4}^{2-}$ at least two functional groups must be in close enough proximity for sorption to take place. This is a further reason why $\mathrm{Cu}(\mathrm{CN})_{4}^{3-}$ does not load onto the Imac HP555s resin, because this would require at least three triethyl groups to be in close proximity for sorption to occur. This is made difficult due to the steric effects associated with the triethyl functional group. In addition, the $\mathrm{Cu}(\mathrm{CN})_{4}^{3-}$ complex is labile and so readily converts to the more stable tricyanocuprite complex (Eq. (2)).

It can also be seen from Table 2 that the mean sorption energies of copper and nickel are only slightly different and these values are not signifi-

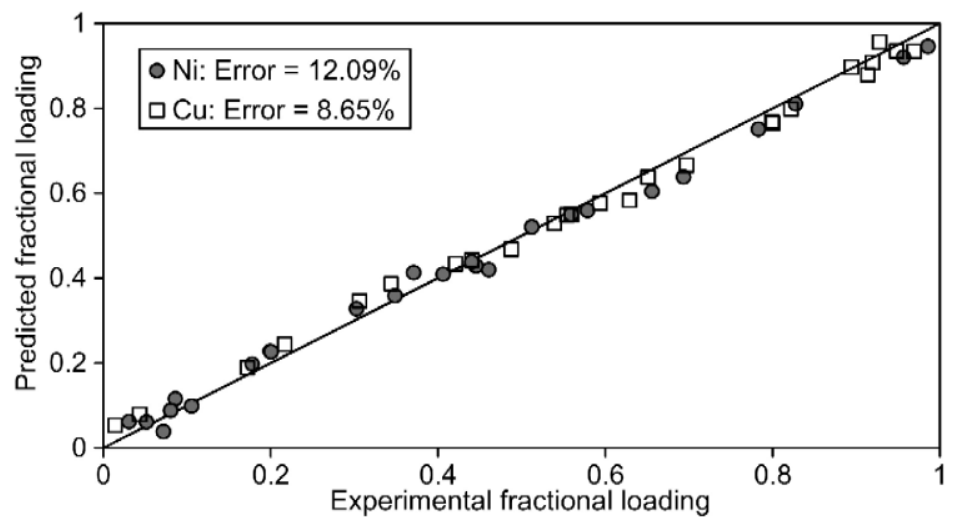

Fig. 5. A comparison between predicted and experimental copper and nickel loading on the Imac HP555s resin. Initial cyanide concentration: $200 \mathrm{mg} / \mathrm{L}$. 
Table 2

Parameters used for the modelling of copper and nickel sorption on Imac HP555s resin containing triethylammonium functional groups

\begin{tabular}{|c|c|c|c|c|c|}
\hline \multirow[t]{2}{*}{ Surface } & \multirow[t]{2}{*}{ Solvent } & \multicolumn{2}{|l|}{$50 \mathrm{mg} / \mathrm{L}$} & \multicolumn{2}{|c|}{$200 \mathrm{mg} / \mathrm{L}$} \\
\hline & & Nickel & Copper & Nickel & Copper \\
\hline $\begin{array}{l}\text { Energy } \\
\text { distribution }\end{array}$ & - & Normal & Normal & Normal & Normal \\
\hline Mean & - & 1 & 1 & 1 & 1 \\
\hline $\begin{array}{l}\text { Standard } \\
\text { deviation }\end{array}$ & - & 0.05 & 0.1 & 0.03 & 0.1 \\
\hline $\begin{array}{l}\text { Selective } \\
\text { sorption }(\%)\end{array}$ & & 100 & 100 & 100 & 100 \\
\hline Species & & & & & \\
\hline $\begin{array}{l}\text { Mean sorption } \\
\text { energy }\end{array}$ & 0 & -17.97 & -15.83 & -18.24 & -15.99 \\
\hline $\begin{array}{l}\text { Interaction } \\
\text { energies }\end{array}$ & 0 & 0 & 0 & 0 & 0 \\
\hline
\end{tabular}

cantly changed whether the concentration of free cyanide used during the sorption experiments was 50 or $200 \mathrm{mg} / \mathrm{L}$. As expected, a less negative value for the mean sorption energy for copper is observed. This is due to the physico-chemical features of the sorbent i.e. the highly hydrophobic character due to the polystyrene-divinylbenzene matrix and also steric effects attributed to the triethylammonium functional groups. The substantially negative values of the sorption energies also represent the high affinity of the resin for both species relative to the solvent. This is to be expected due to the highly polarised metal-tocyanide bonds associated with metal cyanide complexes. This also means that a high proportion of the surface area available for sorption is covered by both copper and nickel complexes.

Upon modelling the equilibrium sorption of gold and copper onto an experimental resin containing tripropylammonium functional groups, Lukey et al. [10] observed that the resin had a higher affinity for the tricyanocuprite complex than for the tetracyancuprite species. This phenomenon was attributed to the presence of the long alkyl chain of the tripropylammonium functional group. This also resulted in the resin having a lower strong base capacity compared with a resin containing trimethylammonium groups. It was proposed in the study by Lukey et al. [10] that the tripropylammonium groups increase the hydrophobicity of the resin and thereby enhance the affinity of the resin for complexes of a low charge. This corresponded to a decrease in the mean sorption energy for copper compared with the other resins studied. Lukey et al. [10] also observed a better model fit when the area available for the sorption of copper was decreased to $92 \%$. This was reasoned to be due to steric hindrance caused by the long alkyl chain of the tripropylammonium functional group. As discussed previously, a restriction in the area available for the sorption of copper did not improve the fit of the model in the present work. However, it is important to note that the Imac HP555s resin contains triethylammonium groups. Therefore, due to the shorter alkyl chain length and the higher strong base capacity of the Imac HP555s resin compared with the tripropylammonium resin, the selective sorption of copper is not expected. In addition, in the current work the copper and nickel cyanide system is investigated. As shown by Fig. 3, the predominant complexes sorbed onto the Imac HP555s resin are $\mathrm{Cu}(\mathrm{CN})_{3}^{2-}$ and $\mathrm{Ni}(\mathrm{CN})_{4}^{2-}$. Both of these complexes are planar in geometry and have the same charge. Consequently, it would be expected that the resin surface available for sorption of both complexes would be the same.

As mentioned previously, the Amberlite IRA958 resin has trimethylammonium functional groups attached to a polyacrylic matrix. The presence of $\mathrm{C}=\mathrm{O}$ groups in the matrix allows the formation of hydrogen bridges with water molecules. This leads to a higher hydration of the resin, represented by its water content $[7,18]$. This results in polyacrylic-based resins having a more hydrophilic character compared with polystyrene resins. Consequently, the Amberlite IRA958 resin has a high affinity for highly charged complexes such as $\mathrm{Fe}(\mathrm{CN})_{6}^{4-}$ and $\mathrm{Cu}(\mathrm{CN})_{4}^{3-}$ compared with polystyrene-based resins. Due to the high charges of these complexes, they have a higher hydration level than cyano-complexes with low valence. As a result, they exhibit a high affinity for hydrophilic resins such as Amberlite IRA958.

The Raman spectra obtained for the Amberlite IRA958 resin loaded with copper and nickel are presented in Fig. 6. The presence of three substantial peaks in the $2070-2110 \mathrm{~cm}^{-1}$ region indicates that $\mathrm{Cu}(\mathrm{CN})_{3}^{2-}$ and $\mathrm{Cu}(\mathrm{CN})_{4}^{3-}$ sorb onto the Amberlite IRA958 resin. It should be noted that there is a shift in the position of the peaks for the sorbed $\mathrm{Cu}(\mathrm{CN})_{4}^{3-}$ 


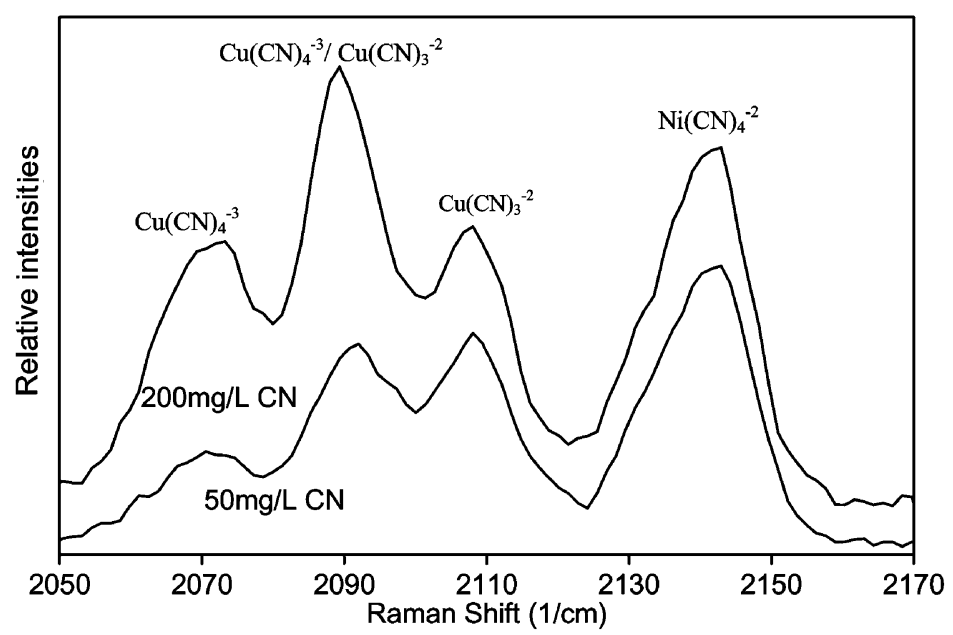

Fig. 6. Raman spectra of copper and nickel cyanides loading on the Amberlite IRA958 resin. The peaks at 2071, 2090, and $2108 \mathrm{~cm}^{-1}$ are related to copper and the peak at $2146 \mathrm{~cm}^{-1}$ corresponds to nickel cyano-complex. Resin loadings: $7.3 \mathrm{mgCu} / \mathrm{mL}$ resin and 10.0 $\mathrm{mgNi} / \mathrm{mL}$ resin for $50 \mathrm{mg} / \mathrm{L} \mathrm{CN}^{-}$solution; $7.5 \mathrm{mgCu} / \mathrm{mL}$ resin and $9.3 \mathrm{mgNi} / \mathrm{mL}$ resin for $200 \mathrm{mg} / \mathrm{L} \mathrm{CN}^{-}$solution.

complex. In aqueous solution the $\mathrm{Cu}(\mathrm{CN})_{4}^{3-}$ complex exhibits peaks at 2078 and $2094 \mathrm{~cm}^{-1}$ (Fig. 1). The peaks for the sorbed complex are located at 2071 and $2091 \mathrm{~cm}^{-1}$ (Fig. 6). The shift in the position of these peaks is attributed to the interaction between the labile $\mathrm{Cu}(\mathrm{CN})_{4}^{3-}$ complex and the polyacrylic resin matrix. The slight shift in these peaks to lower Raman values was also observed when Amberlite IRA958 was loaded with copper cyanide only. Consequently, this phenomenon is not due to the sorption of nickel cyanide on the resin (Fig. 6). It is noteworthy that Coleman et al. [23] also observed a shift in the position of the absorption peaks for copper cyano-complexes sorbed on the quaternary ammonium resin, Dowex 1-X10.

It was discussed previously that the $\mathrm{Cu}(\mathrm{CN})_{4}^{3-}$ complex is the predominant species in solution when the free cyanide concentration is $1000 \mathrm{mg} / \mathrm{L}$ (Fig. 1). This is because the relative intensity of the peak observed at $2078 \mathrm{~cm}^{-1}$ (characteristic of $\mathrm{Cu}(\mathrm{CN})_{4}^{3-}$ ) in Fig. 1 is greater than the relative intensity of the peak at $2108 \mathrm{~cm}^{-1}$ (characteristic of $\mathrm{Cu}(\mathrm{CN})_{3}^{2-}$ ).

The relative distribution of copper cyanide species sorbed on Amberlite IRA958 can be obtained by comparing the relative intensities of Raman peaks assigned to each copper complex (Fig. 6). It is shown by Fig. 6 that the Amberlite IRA958 resin loaded both $\mathrm{Cu}(\mathrm{CN})_{3}^{2-}$ and $\mathrm{Cu}(\mathrm{CN})_{4}^{3-}$ when the sorption solution had a free cyanide concentration of approximately $50 \mathrm{mg} / \mathrm{L}$. The loading of $\mathrm{Cu}(\mathrm{CN})_{3}^{2-}$ is prominent in view of the intense peak at 2108 $\mathrm{cm}^{-1}$. The overlapping of shifted peaks at 2091 $\mathrm{cm}^{-1}$ makes it difficult to quantify the loading of $\mathrm{Cu}(\mathrm{CN})_{4}^{3-}$, but the shifted peak at $2071 \mathrm{~cm}^{-1}$ indicates that some $\mathrm{Cu}(\mathrm{CN})_{4}^{3-}$ is indeed present. At a free cyanide concentration of $200 \mathrm{mg} / \mathrm{L}$ the shifted peak at $2071 \mathrm{~cm}^{-1}\left(\mathrm{Cu}(\mathrm{CN})_{4}^{3-}\right)$ is more dominant than at a lower cyanide concentration, and the shifted overlapping peak at $2091 \mathrm{~cm}^{-1}$ becomes more significant relative to the peak at $2108 \mathrm{~cm}^{-1}(2108$ $\left.\mathrm{cm}^{-1}\right)$. This suggests that $\mathrm{Cu}(\mathrm{CN})_{4}^{3-}$ is present in relatively higher concentrations than $\mathrm{Cu}(\mathrm{CN})_{3}^{2-}$ at these higher cyanide concentrations. It is important to note that the ion exchange resins studied do not possess a high affinity for free cyanide. These results are expected because it is shown by Fig. 1 that for the experiments at $1000 \mathrm{mg} / \mathrm{L} \mathrm{CN}^{-}$the concentration of $\mathrm{Cu}(\mathrm{CN})_{3}^{2-}$ in solution is lower than at 250 $\mathrm{mg} / \mathrm{L}$ - the relative intensity of the peak at 2108 $\mathrm{cm}^{-1}$ (characteristic of $\left(\mathrm{Cu}(\mathrm{CN})_{3}^{2-}\right.$ ) is lower. Conversely, at $1000 \mathrm{mg} / \mathrm{L}$ cyanide the concentration of $\mathrm{Cu}(\mathrm{CN})_{4}^{3-}$ species in solution is higher than at the lower cyanide concentration.

The parameters used to model the equilibrium sorption of copper and nickel cyano-complexes on the polyacrylic resin, Amberlite IRA958, are pre- 
Table 3

Parameters used to model the equilibrium sorption of copper and nickel onto the Amberlite IRA958 resin, which contains trimethylammonium functional groups

\begin{tabular}{|c|c|c|c|c|c|c|c|}
\hline \multirow[t]{2}{*}{ Surface } & \multirow[t]{2}{*}{ Solvent } & \multicolumn{3}{|l|}{$50 \mathrm{mg} / \mathrm{L}$} & \multicolumn{3}{|c|}{$200 \mathrm{mg} / \mathrm{L}$} \\
\hline & & Nickel & Copper & & Nickel & Copper & \\
\hline Energy distribution & - & Normal & Normal & Normal & Normal & Normal & Normal \\
\hline Distribution fraction & - & - & 0.42 & 0.58 & - & 0.35 & 0.65 \\
\hline Mean & - & 1 & 0.8 & 1 & 1 & 0.8 & 1 \\
\hline Standard deviation & - & 0.05 & 0.05 & 0.2 & 0.05 & 0.05 & 0.2 \\
\hline Selective sorption $(\%)$ & & 100 & 100 & & 100 & 100 & \\
\hline \multicolumn{8}{|l|}{ Species } \\
\hline Mean sorption energy & 0 & -19.40 & -21.28 & & -19.87 & -22.31 & \\
\hline Interaction energy & 0 & 0 & 0 & & 0 & 0 & \\
\hline
\end{tabular}

sented in Table 3. As shown by Figs. 7 and 8, the sorption of both metals on the resin has been modelled successfully. It can be seen from Table 3 that the mean sorption energy for copper is slightly more negative than that for nickel. In addition, the values of these parameters did not change significantly with an increase in the free cyanide concentration from 50 to $200 \mathrm{mg} / \mathrm{L}$.

As indicated by Figs. 1 and 6 , the $\mathrm{Ni}(\mathrm{CN})_{4}^{2-}$ complex is the only nickel species present in solution and also sorbed onto the resin. For this reason, a unimodal Normal distribution is used to describe the surface heterogeneity of the resin experienced by the nickel cyanide complex. It can also be seen from Fig. 6 that both copper complexes sorb onto the Amberlite IRA958 resin. Consequently, a bimodal
Normal distribution has been used to describe the surface heterogeneity experienced by the copper cyanide complexes. As shown by Table 3, a distribution fraction of 0.42 and 0.35 (for 50 and $200 \mathrm{mg} / \mathrm{L}$ cyanide, respectively) is used to specify the bimodal Normal distribution. The latter value corresponds to a higher proportion of $\mathrm{Cu}(\mathrm{CN})_{4}^{3-}$ on the resin (Fig. 6). According to Lukey et al. [10,11] the mean sorption energy parameter is related to the electrical interaction between the ion exchange resin and the sorbed metal cyanide complex. Therefore, from classical ion exchange theory this means that a more highly charged species would have a greater affinity for the resin. In the model, this increased affinity for the resin corresponds to a more negative mean sorption energy.

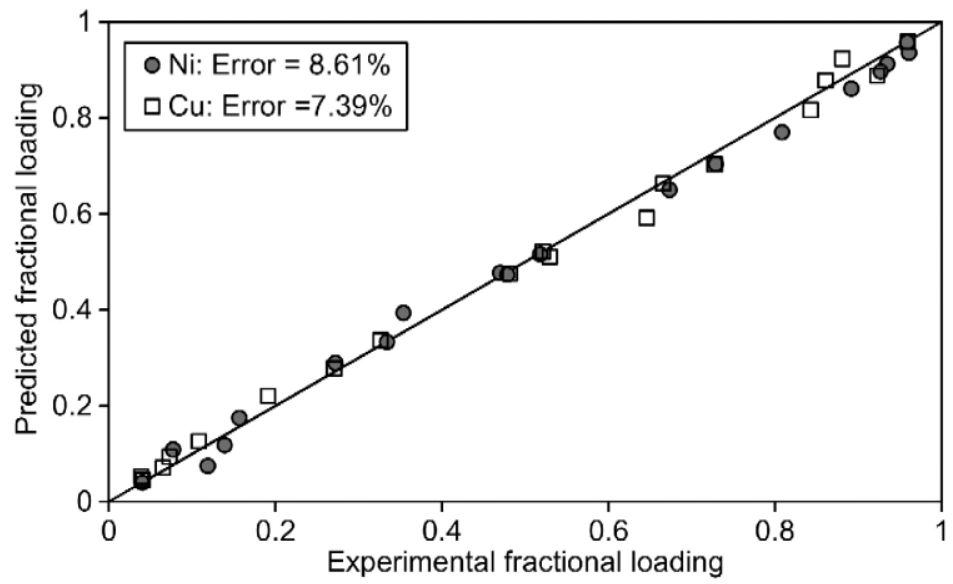

Fig. 7. A comparison between predicted and experimental copper and nickel loading on the Amberlite IRA958 resin. Initial cyanide concentration: $50 \mathrm{mg} / \mathrm{L}$. 


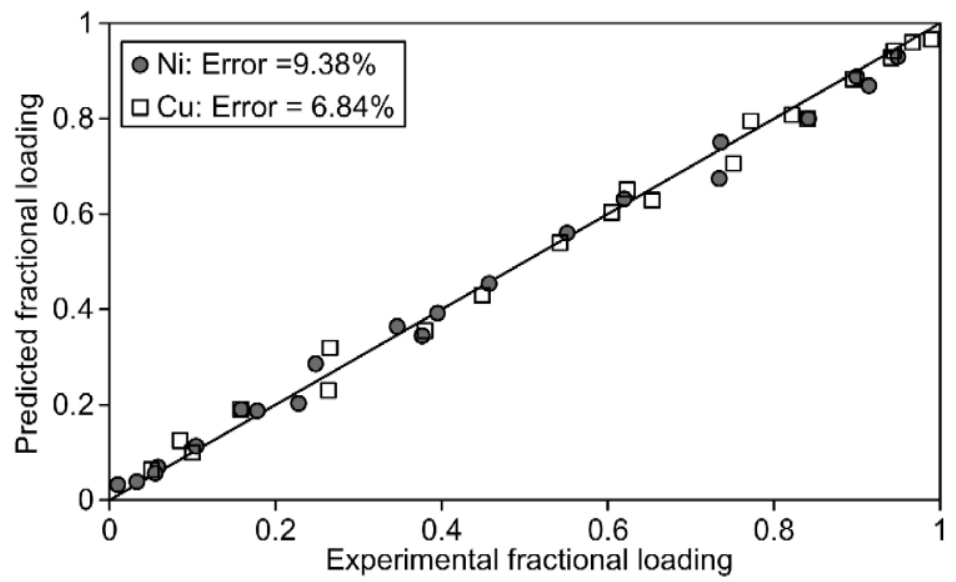

Fig. 8. A comparison between predicted and experimental copper and nickel loading on the Amberlite IRA958 resin. Initial cyanide concentration: $200 \mathrm{mg} / \mathrm{L}$.

From Table 3 it can be seen that the mean sorption energy of copper is slightly more negative than that of nickel. This is attributed to the presence of both $\mathrm{Cu}(\mathrm{CN})_{3}^{2-}$ and $\mathrm{Cu}(\mathrm{CN})_{4}^{3-}$ on the resin. As the $\mathrm{Cu}(\mathrm{CN})_{4}^{3-}$ complex has a more negative charge than the $\mathrm{Ni}(\mathrm{CN})_{4}^{2-}$ complex, a more negative sorption energy is expected. Limiting the surface area available for the sorption of either copper or nickel did not improve the fit of the model to the sorption data. However, selective sorption of either copper or nickel is not expected to take place in the Amberlite IRA958 system because this resin is hydrophilic and contains trimethylammonium groups. As a consequence, the affinity of the resin for copper or nickel cyanide complexes is not affected by their geometry or extent of co-ordination.

Comparing the mean sorption energies of copper and nickel for the two resins studied (Tables 2 and 3 ), it can be seen that these values are more negative for the Amberlite IRA958 resin than the Imac HP555s resin. Although the concentration of exchange groups (the strong base capacity) is higher for the Amberlite IRA958 resin compared with Imac HP555s, this alone does not account for the differences in sorption energy. Of more importance is the difference in resin matrix and also functional group on each of the two resins. As expected, the model indicates that the energy associated with the sorption of copper and nickel onto Amberlite IRA958 is more negative (i.e. stronger sorption) than for Imac HP555s. This is because Amberlite IRA958 has a greater hydrophilicity due to its polyacrylic matrix compared with the polystyrene-based Imac HP555s. The difference in the resin functional groups has also been shown to affect the mean sorption energies.

The results of the present work show that both resins can be used for the sorption of the cyano-complex of nickel, while the Imac HP555s resin is more suitable for the loading of copper in solutions where $\mathrm{Cu}(\mathrm{CN})_{3}^{2-}$ is the predominant species. However, the successful elution of metals from each of these resins is an important consideration. Most of the proposed elution procedures are based on the acidification of the resin in an AVR-like procedure. While nickel cyanide can be directly decomposed to $\mathrm{Ni}^{2+}$ and free cyanide, the acidification of resins that contain a high concentration of copper cannot be carried out unless sufficient acid or a complexing agent is applied. This is necessary because in the case of direct acidification, copper decomposes to the very stable $\mathrm{CuCN}$ precipitate. The decomposition reaction is accompanied by the liberation of $\mathrm{HCN}$ :

$$
\mathrm{Cu}(\mathrm{CN})_{n}^{1-n}+(n-1) \mathrm{H}^{+} \leftrightharpoons \mathrm{CuCN}+(n-1) \mathrm{HCN}
$$

The $\mathrm{CuCN}$ precipitate could lead to the poisoning of the ion exchange resin. Thiourea is capable of replacing the cyanide ligand in the complex, thereby 
producing a cationic species that does not load onto the resin. It has been shown previously that an acidified $\left(\mathrm{H}_{2} \mathrm{SO}_{4}\right)$ thiourea solution is able to elute more than $90 \%$ of copper and nickel loaded onto Imac HP555s as well as a resin with the same polyacrylic matrix as Amberlite IRA958 [17].

As discussed above, the sorption of cyano-complexes onto ion exchange resins relies on the chemical features of both the complex and the resin. If the metal can form more than one complex the resin may have a higher affinity for one of these complexes. The present study has shown that the factors which affect the affinity of the resin for metal cyanide complexes include: the charge of complex, hydrophobic/hydrophilic character of the resin, type of matrix, and also steric effects such as the alkyl chain length of the functional group.

The affinity of the Dowex A1 resin for the $\mathrm{Ag}(\mathrm{CN})_{2}^{-}$complex in the $\mathrm{Ag}-\mathrm{CN}$ system [19], the precipitation of $\mathrm{AuCN}$ in a polydiallylamine [20,21] and the results of the present work show a change in the nature of the species upon sorption onto a resin. On the other hand, it was also shown that there is no change in the speciation of copper or nickel during sorption onto the polydiallylamine resin [20,21]. It was also shown in the present study that the speciation of nickel was the same in solution and on the sorbent. These results indicate that the mechanisms of sorption are specific for each system under consideration. The generalisation of sorption studies to broader environments should be carried out considering the differences in the nature of the solutions and the resins used during these studies. The sorption behaviour of copper and nickel on the Imac HP555s and IRA 958 resins is dependent upon the hydrophobic nature of the ions and the resins themselves. The type of functional group on the resin is also an important consideration, because it is has been shown in the current work that the triethylammonium functional group increases the steric hindrance in the system.

\section{Conclusions}

Raman spectroscopy has been used to determine the metal cyanide speciation in solution and also sorbed onto two different ion exchange resins. It has been established that the Imac HP555s resin loads $\mathrm{Ni}(\mathrm{CN})_{4}^{2-}$ and $\mathrm{Cu}(\mathrm{CN})_{3}^{2-}$. However, the sorption of $\mathrm{Cu}(\mathrm{CN})_{4}^{3-}$ on the Imac HP555s resin was not observed. It is proposed that the predominant sorption of $\mathrm{Cu}(\mathrm{CN})_{3}^{2-}$ onto the Imac HP555s resin is due to the sterically bulky triethylammonium group and also the hydrophobic polystyrene-divinylbenzene matrix. Conversely, the Amberlite IRA958 resin loads $\mathrm{Ni}(\mathrm{CN})_{4}^{2-}$ as well as both $\mathrm{Cu}(\mathrm{CN})_{3}^{2-}$ and $\mathrm{Cu}(\mathrm{CN})_{4}^{3-}$ complexes. It is proposed that the sorption of the cuprous tetracyano complex is due to the hydrophilic nature of the polyacrylic matrix and also the greater concentration of exchange groups on Amberlite IRA958 compared to the Imac HP555s resin.

The equilibrium sorption behaviour of copper and nickel cyano-complexes on the Imac HP555s resin and the Amberlite IRA958 resin has been successfully described using a mathematical model based on statistical thermodynamic principles. The advantage of this modelling approach over models proposed previously is that it uses parameters that have a fundamental meaning. In particular, the Raman spectroscopic results regarding metal cyanide speciation have been used to provide estimates of parameter values in the model. It has been found for the Imac HP555s resin (polystyrene-divinylbenzene matrix) that nickel has a slightly more negative sorption energy than copper. In contrast, it has been found for Amberlite IRA 958 (polyacrylic matrix) that copper has a slightly more negative sorption energy than nickel.

It was found for both resins that the concentration of free cyanide (either 50 or $200 \mathrm{mg} / \mathrm{L}$ ) during sorption did not affect the model parameters significantly. The results of the present study show that the Amberlite IRA958 resin can be used for the sorption of copper and nickel cyanide complexes, while the Imac HP555s resin is not recommended for the recycling of cyanide from solutions containing a high $\mathrm{CN} / \mathrm{Cu}$ ratio. For the first time, the equilibrium sorption behaviour of copper and nickel on both resins studied has been successfully described. By combining Raman spectroscopy and a probabilistic model a greater understanding of the equilibrium sorption of both metals onto ion exchange resins has been achieved. 


\section{Acknowledgements}

This work was supported by Conselho Nacional de Pesquisas, CNPq, Brazil and by RECOPE and PRONEX grants. The assistance of Dr. Shane T. Huntington from the Particulate Fluids Processing Centre (PFPC), The University of Melbourne is also appreciated.

\section{References}

[1] N. Headley, H. Tabachnick, Chemistry of cyanidation. Mineral Dressing Notes, vol. 17, American Cyanamid, 1950, 54 pp.

[2] P.A. Riveros, D. Koren, V.M. McNamara, J. Binvignat, Cyanide recovery from a gold mill barren solution containing high levels of copper. CIM Bull. 91 (1025) (1998) 73-81.

[3] P.A. Riveros, R. Molmar, F. Basa, Treatment of a highcyanide waste solution for cyanide and metal recovery. CIM Bull. 89 (998) (1996) 153-156.

[4] V.A. Leão, R.S. Costa, V.S.T. Ciminelli, Cyanide recycling using strong base ion exchange resins. J. Met. 50 (10) (1998) 71-74.

[5] L. Whittle, in: H. von Michaelis (Ed.), The Piloting of Vitrokele for the Cyanide Recovery and Waste Management at Two Canadian Gold Mines, Randol Gold Forum '92, Vancouver, Canada. Randol International Ltd., Golden, CO, USA, 1992, pp. 379-384.

[6] C.A. Fleming, in: B. Mishra (Ed.), The potential role of anion exchange resins in the gold industry. EPD Congress 1998, TMS, San Antonio, TX, USA, 1998, pp. 95-117.

[7] V.A. Leão, V.S.T. Ciminelli, Application of ion exchange resins in gold hydrometallurgy. A tool for cyanide recycling. Solvent Extr. Ion Exch. 18 (3) (2000) 567-582.

[8] S.R. La Brooy, H.G. Linge, G.S. Walker, Review of gold extraction from ores. Miner. Eng. 7 (10) (1994) 1213-1241.

[9] F.P. De Kock, A Generalised Competitive Adsorption Theory of Non-Ideal Substances, PhD Thesis, The University of Stellenbosch, South Africa, 1995, 218 pp.

[10] G.C. Lukey, J.S.J. Van Deventer, D.C. Shallcross, Equilibrium model for the selective sorption of gold cyanide on different ion-exchange functional groups. Miner. Eng. 13 (12) (2000) 1243-1261.
[11] G.C. Lukey, J.S.J. Van Deventer, D.C. Shallcross, Equilibrium model for the sorption of gold cyanide and copper cyanide on trimethylamine resin in saline solutions. Hydrometallurgy 59 (1) (2000) 101-113.

[12] W.C. Lenahan, R.D.L. Murray-Smith, Assay and Analytical Practice in South African Mining Industry, Johannesburg. SAIMM, Johannesburg, South Africa, 1986.

[13] G.C. Lukey, J.S.J. Van Deventer, S.T. Huntington, R.L. Chowdhury, D.C. Shallcross, Raman study on the speciation of copper cyanide complexes in highly saline solutions. Hydrometallurgy 53 (9) (1999) 233-244.

[14] A. Terzis, K.N. Raymond, T.G. Spiro, On the structure of $\mathrm{Ni}(\mathrm{CN})_{5}^{3-}$. Raman Infrared and X-Ray Crystallographic Evidence. Inorganic Chemistry 9 (11) (1970) 2415-2420.

[15] A.G. Sharpe, The Chemistry of Cyano Complexes of the Transition Metals. Academic Press, London, 1976302 pp.

[16] R.S. Costa, V.A. Leão, V.S.T. Ciminelli, Copper and cyanide recovery using ion exchange resins. ALTA Copper 1999Copper Sulphides Symposium and Copper Hydrometallurgy Forum September 6-8, Gold Coast, Queensland, Australia. ALTA Metallurgical Services Ltd., Victoria, Australia, 1999.

[17] V.A. Leão, R.S. Costa, V.S.T. Ciminelli, Cyanide recycling using ion exchange resins-application to the treatment of gold-copper ores. in: Massaci (Ed.), XXI International Mineral Processing Congress, Rome, Italy, vol. A, 2000, pp. A6:1-A6:9.

[18] P.A. Riveros, Selectivity aspects of the extraction of gold from cyanide solutions with ion exchange resins. Hydrometallurgy 33 (1993) 43-58.

[19] L.H. Jones, R.A. Penneman, Infrared absorption studies of aqueous complex ions: I. Cyanide complexes of $\mathrm{Ag}(\mathrm{I})$ and $\mathrm{Au}(\mathrm{I})$ in aqueous solution and adsorbed on anion resin. $\mathrm{J}$. Chem. Phys. 22 (6) (1954) 965-970.

[20] C.F. Vernon, P.D. Fawell, C. Klauber, XPS investigation of the states of sorption of aurocyanide onto crosslinked polydallylamine and commercial anion exchange resins. React. Polym. 18 (1) (1992) 35-45.

[21] P.D. Fawell, C.F. Vernon, C. Klauber, H.G. Linge, The extraction of metal cyanides by crosslinked polydiallylamine. React. Polym. 18 (1) (1992) 57-65.

[22] P.A. Riveros, W.C. Cooper, Speciation study on the ion exchange extraction of silver, copper, iron and zinc cyano complexes with an iterative slope analysis technique. Solvent Extract. Ion Exch. 3 (6) (1993) 909-930.

[23] J.S. Coleman, R. George, L. Allaman, L.H. Jones, Stepwise formation of cyanide complexes of Copper(I) in anion exchangers. J. Phys. Chem. 72 (7) (1968) 135-139. 